\title{
Communication and Effective Policing in Nigeria
}

\author{
Ibikunle Olayiwola Ajisafe*, Ibitoye Pius Odunayo \\ Communication And Media Programme Afe Babalola University Ado Ekiti
}

*Corresponding Author: Ibikunle Olayiwola Ajisafe, Communication And Media Programme Afe Babalola University Ado Ekiti

\begin{abstract}
Poor Communication problem has greatly influenced the performance of the Police Force in Nigeria. Primary among the ever-recurring and persistent problems in the field of police management is that concerned with developing and maintaining an effective systems of communication. Internal communication has to do with decision making, a step in the administrative process which is often ignored and poorly performed. The study analyzed the present system of communication and effective policing in Nigeria through the adoption of Descriptive Research Design Methodology. Secondly, the study collected both qualitative and quantitative data. In the collection of data from respondents, two different sets of questionnaire were prepared. The study employed primary data. The primary data was collected using the CEPSQ (Communication and Effective Policing Survey Questionnaire). Furthermore, equations were solved by the use of statistical model where SPSS was applied. In order to test the significance of the model in assessing the impact of communication in effective policing, the study conducted an Analysis of Variance (ANOVA). On extracting the ANOVA statistics, the study looked at the significance value. The study was tested at $95 \%$ confidence level and 5\% significant level. The result of the study show that there is an urgent need for government intervention in the Police Force through investment on ICT and communication skills. In addition, the study also recommended thatCommunication is a two-way process. In order to make a proper decision, the police executive should have available information and knowledge within the department, some which may be quite removed from him. If decisions are to be effective, unobstructed flow of information to the top of the department must be assured.
\end{abstract}

\section{INTRODUCTION}

A major problem in Nigerian Policing is that of Communication. Primary among the ever-recurring and persistent problems in the field of police management is that concerned with developing and maintaining an effective systemsof communication.Communication is the primary vehicle for bringing about agreement between all the members of a department as to the police objectives. It is thebase for a common and continuing understanding of problems and accomplishmentsexperienced in the day to day pursuits toward the objectives.Most writers in the field of police management have treated the subject of communication as purely a technical problem, concerned primarily with police teletype,telephone, telegraph, and radio facilities, having to do with communication betweenheadquarters and the field or between departments. This has led to a one sidedapproach which does not provide an understanding of internal departmental communication so vital to administration.

According to Oyemwinmina (2016), "the standard of policing available to nation determines the level of development of that country. Unfortunately, the Nigeria police has not been able to live up to expectation in providing adequate security to the nation". Several factors are responsible for policeinefficiency and ineffectiveness, which include corruption, poor funding bygovernment and lack of confidence by the general public.The integrity of the Nigeria police has been eroded by the ineffectiveness andinefficiency in their constitutional responsibilities to the society. As a nation, oursecurity report has now been worse.

Terrorism visited their targets at will; armedrobbers hold up towns to ransom for hours as if in stubborn defiance while reports ofritual killings are on the increase, and kidnappings continue unabated. Standingbetween the wave of crime and the people is the police force that seems to have caughtunprepared (Nwachukwu, 2012).

\subsection{Statement of the Problem}

Poor Communication problem has greatly influenced the performance of the Police Force in Nigeria. Primary among the ever-recurring and persistent problems in the field of police management is that 
concerned with developing and maintaining an effective systemsof communication.Internal communication has to do with decision making, a step in the administrative process which is often ignored and poorly performed. Common practice isto order plans into effect without any consideration of the manner in which they canbe brought to influence the behavior of individual members of the group. Tendenciesare to not follow-up to see if procedures which have been promulgated are used bythe individuals to guide their decisions. Failures in communication result wheneverit is forgotten that human behavior on the part of the individual is the tool withwhich organization achieves its purpose.

\section{AIM AND OBJECTIVES OF THE STUDY}

The aim of this study is to investigate the role of communication for effective policing in Nigeria. In addition, the specific objectives of the study include to:

i) analyze the present system of policing in Nigeria

ii) review concepts of communication and effective policing

iii) provide useful suggestions on improving the present system of policing in Nigeria.

\subsection{Statement of the Research Questions}

The following Research Questions were considered for the Study:

i) What is the role of communication in effective policing?

ii) What is the level of ICT applications in Nigerian Policing?

iii) What is the level of communication-friendliness between the police and masses in Nigeria?

\subsection{Statement of Hypotheses}

The following hypotheses of the study was formulated in null form:

$\mathrm{H}_{0}$ : There is no significant relationship between communication and effective policing in Nigeria

$\mathrm{H}_{\mathrm{i}}$ : There is significant relationship between communication and effective policing in Nigeria

\subsection{Significance of the Study}

The benefit of the study encompasses relevant theories in communication and effective policing. Communication still remains the cardinal point for effective policing in Nigeria. This is also because the policing in Nigeria go alongside with communication. In other words, this study will be beneficial to the Nigerian Police Force and other Security Agencies in Nigeria.

\subsection{Scope of the Study}

It is very important to define the beginning and end of this study. This study only focuses on relevant communication and policing theories in order to improve the present system of policing in Nigeria.

\subsection{Definition of Operational Terms}

The following operational terms were adequately defined in order to shed more light on the study:

Communication: Communication can be defined as the concept of exchanging information between entities.

Policing: This is the application of a civil force to enforce the law in order to maintain public order.

\section{REVIEW OF RELATED LITERATURES}

This section involved the study of related literatures on the following areas which include: the concept of communication in Nigeria, the concept of policing in Nigeria, the theory of communication and policing,and empirical review.

\subsection{Conceptual Framework}

The following concepts were addressed in the study:

i) PoliceCommunication in Nigeria

ii) Perception of Policing in Nigeria 


\subsection{Police Communication in Nigeria}

Police face other communications hurdles as well. One of the most significant is the complexity of the issues they must explain to the public. To effectively communicate with the public, the police must not only figure out how to use the traditional media more effectively, they have to understand and master all of the new and emerging communications technologies. They also have to be much more aware of how the public obtains information and use the methods that are most likely to reach the targeted audiences.Communication plays an important role in any organization. Specifically,research indicated that communication between supervisors and employees is linked toemployee production, trust within the organization andamong its member and personal feelings andperceptions held by subordinates.

\subsection{Perception of Policing in Nigeria}

Although crime reduction has taken center stage as a measure of police effectiveness(particularly with politicians), the police are engaged in a significant amount of work thatis not directly related to crime but is important to an overall sense of safety. They spend aconsiderable amount of time dealing with traffic issues, handling calls for service, specialevents, disputes, security alarm calls, and many other non-crime problems. Traditional measures that have taken a back seat to reported crime include response time,traffic statistics such as collisions and enforcement, case clearances, arrests, communityproblem solving efforts, and overall citizen satisfaction. Where can the public find out aboutpolice performance in areas other than crime? How do the police effectively communicateabout this aspect of their work? What should they be talking about? In addition, a resident's personal experience with police is nearly as important as the resident'simpression of the neighborhood and quality of life in determining his or hersatisfaction with police.

\subsection{Empirical Review}

Ingram et al (2013) collected survey data from Seven Hundred and Sixty-Five Patrol Officers (765) and 146 Sergeants across five police departments and found that sergeant attitudes do not directly affect official attitude towards communication.

Famega et al (2005) adds to findings related to communication and perceptions between supervisors and their subordinates. According to them, "there is high level of communication deficiency between supervisors and their subordinates.

Jablin (1979) suggested that for effective communication to work among the police and clients, the willingness of superiors and subordinates to communicate relied heavily on the perceptions of one another's willingness to listen.

\subsection{Theory of Communication and Policing}

Communication is the process of transmitting cues, mainly written and verbal, in order to modify human behavior.' It is a process through which interaction betweenmembers of a police department is made possible. As such, it is a carrier of a socialprocess by which police executives influence and, in turn, are influenced by subordinate officers.Accordingly, it is grounded in the interchange of ideas, and in thisrespect it involves the broad field of human interchange of thoughts, ideas. opinions.and attitudes, which are primarily designed to modify human behavior.With reference to a police department, this process involves three steps. Someone in the department must initiate the communication, (2) someone must transmitit from its source to its destination, and (3) the communication must make itsimpact upon the recipient. In the course of these steps, there are opportunities for'misinterpretation and misunderstanding.The manner in which the communication process occurs between members of adepartment is rather common knowledge. Most communications follow either theformal lines of authority reflected in the departmental organization chart, or informalchannels, which are the unplanned channels of communication operating along sidebut apart from the formal structure.

Good administration requires that there be clear channels for funneling information, opinions, and attitudes of all members of a department upward, downward andhorizontally throughout the organization. This requires that the formal organizationof the department be based on sound principles of organization which are religiouslyadhered to at all times. A good communication system provides the media for passing information fromthe chief of police to all levels of the departmental hierarchy with a return of information signifying receipt by subordinates and a carrying out of desired 
obligations. The chief of police must be assured that his directions are received by subordinatesand that the subordinates interpret and effect directives in a manner intended.Communications cannot occur until information is understood by the receiver,nor is it complete as far as administration is concerned until the receiver is motivated to carry it out. The benefits which police executives can realize by the free flow ofinformation upward, with respect to subordinates' interpretation and reaction to decisions.

\section{Methodology}

This section sets out various stages that were followed in completing the study. It specifically covers the research design, population, data collection instruments, and data analysis.

\subsection{Research Design}

The Research design shed light on qualitative and quantitative methods of data collection, as we ensured absorption of the relevant information during the cause of our feasibility study. The population of the study covered the details of respondents of the study surveys. Furthermore, the sampling technique for the study was improved through the adoption of simple random sampling technique. In addition, the techniques of data analysis used for the study included descriptive and inferential statistics.

\subsection{Area of Study}

The area of study includes five Divisional Police Headquarters in Uyo capital of Akwa - Ibom State, Nigeria.

\subsection{Population of the Study}

Non probability convenient sampling was utilized to secure participants for the study. This type of sampling involves choosing participants on the basis of their availability and some features or .process that may be of interest for a particular study. For the current study, some of the staffs of Divisional Police Headquarters in Akwa Ibom State served as respondents. In addition, sample questionnaires were issued to the respondents in order to analyze and also recommend solutions for communication and effective policing in Nigeria.

\subsection{Sampling Size}

Sampling involves the selection of a portion of the finite population being studied. Non-probability sampling does not attempt to select a random sample from the population of interest. A total of Seventy (70) respondents which comprises of some staffs of the Nigerian Police Force availed themselves for the administration of sample survey questionnaires for data extraction.

\subsection{Sources of Data}

In this research, the researcher collected both qualitative and quantitative data.In the collection of data from respondents, two different sets of questionnaire were prepared. The study employed primary data. The primary data was collected using the CEPSQ (Communication and Effective Policing Survey Questionnaire)

\subsection{Reliability and Validity of the Instrument}

The equation was solved by the use of statistical model where SPSS was applied. In order to test the significance of the model in assessing the impact of market segmentation in organizational production and planning, the study will conduct an Analysis of Variance (ANOVA). On extracting the ANOVA statistics, the researcher looked at the significance value. The study was tested at $95 \%$ confidence level and 5\% significant level. If the significance number found is less than the critical value ( ) set 2.4 , then the conclusion was that the model is significant in explaining the relationship.

\subsection{Techniques in Data Analysis}

Data analysis has two prominent methods: qualitative research and quantitative research. Each method has its own techniques. Interviews and observations are forms of qualitative research, while experiments and surveys are quantitative research.

\section{RESULTS AND DISCUSSION}

\subsection{Data Presentation}

This section discusses the interpretation and presentation of the findings obtained from analysis of Communication and Effective Policing in Nigeria. Secondly, descriptive and inferential statistics were 
used to discuss the findings of the study. The study targeted a population size of Seventy (70) respondents from which all filled and returned the questionnaires, making a response rate of $100 \%$. This response rate was satisfactory to make conclusions for the study.

\subsection{Data Analysis}

Table1. Gender of the Respondents

\begin{tabular}{|l|l|l|}
\hline SEX & FREQUENCY & PERCENTAGE (\%) \\
\hline Male & 47 & 67.14 \\
\hline Female & 23 & 32.86 \\
\hline Total & $\mathbf{7 0}$ & $\mathbf{1 0 0}$ \\
\hline
\end{tabular}

Source: Research Findings

Majority of the respondents were males and made up a percentage rate of $67.14 \%$, while the remaining $32.86 \%$ comprised of the females in the location of the study.

Table2. Marital Status of the Respondents

\begin{tabular}{|l|l|l|}
\hline MARITAL STATUS & FREQUENCY & PERCENTAGE (\%) \\
\hline Single & 18 & 25.71 \\
\hline Married & 52 & 74.29 \\
\hline Total & $\mathbf{7 0}$ & $\mathbf{1 0 0}$ \\
\hline
\end{tabular}

Source: Research Findings

Majority of the respondents were married. This further showed maturity in communicating with their respective spouses. While 25.71 of the respondents were single.

Table3. There is a very strong relationship between communication and effective policing in Nigeria

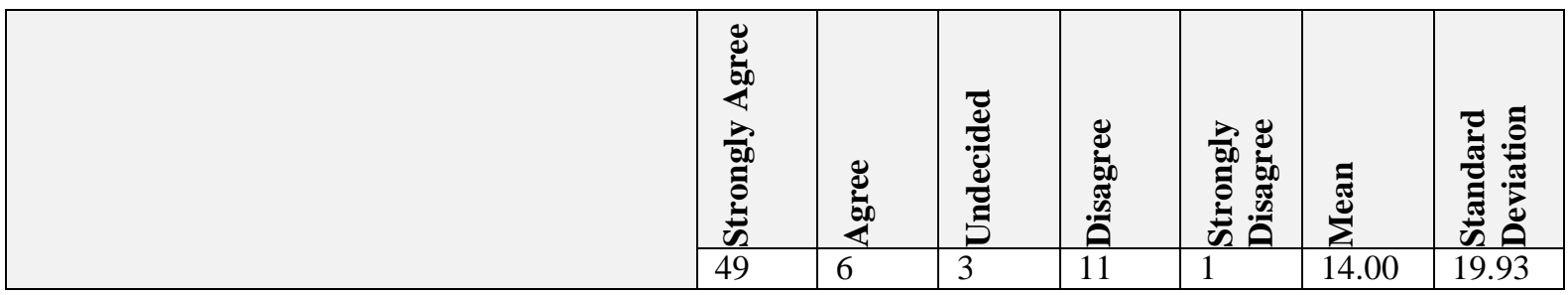

Source: Research Findings

Majority of the respondents strongly agreed to the impeccable role of communication in effective policing in Nigeria, and also clamored for its improvement.

Table4. Police Partnership with media organizations is a flavored tool for effective policing in Nigeria

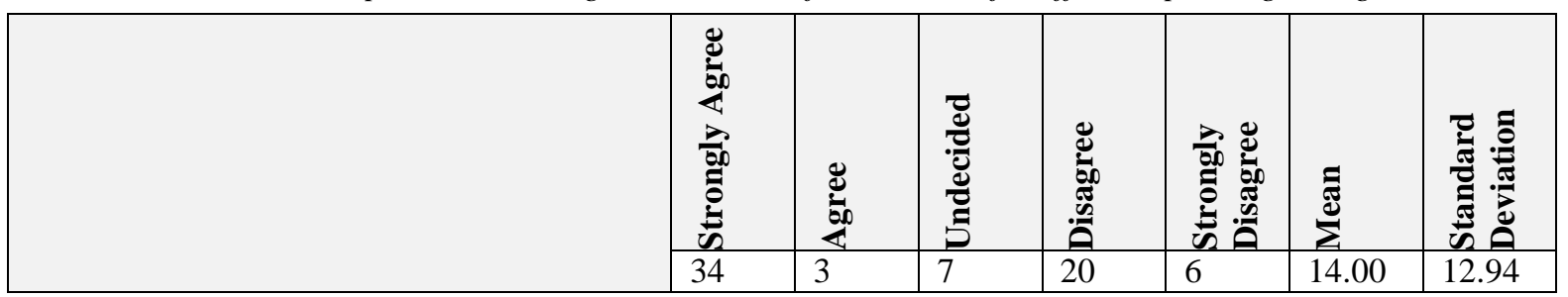

Source: Research Findings

The partnership of the police and relevant media organizations is another unique way for strengthening communication and effective policing in Nigeria. This was further confirmed by 34 respondents that strongly agreed.

Table5. The evaluation and improvement of Public Relation Services will catalyze confidence building between the police and public

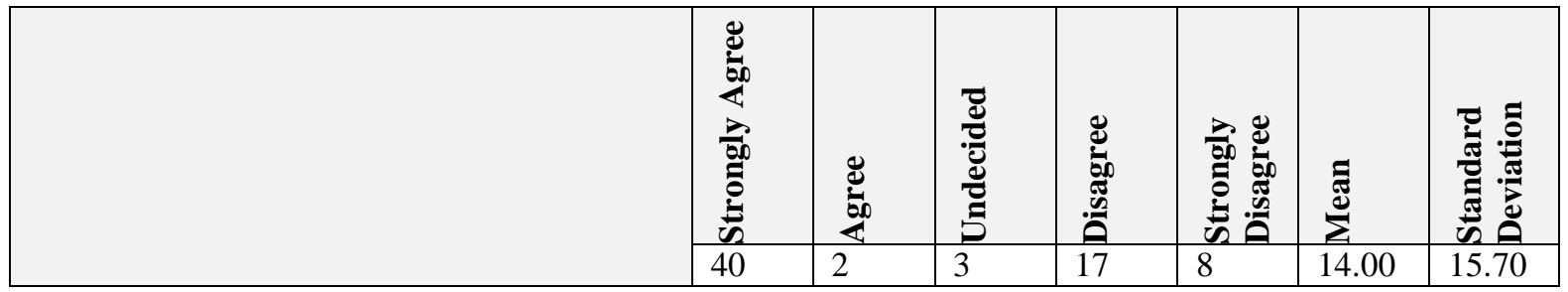

Source: Research Findings 
Most of the respondents supported the need for re-evaluation and improvement of the present system of public relation service in the Nigerian Police Force.

Table6. The Design, Development and Application of a Centralized Security Information System is a Welcomed Development for Communication Improvement

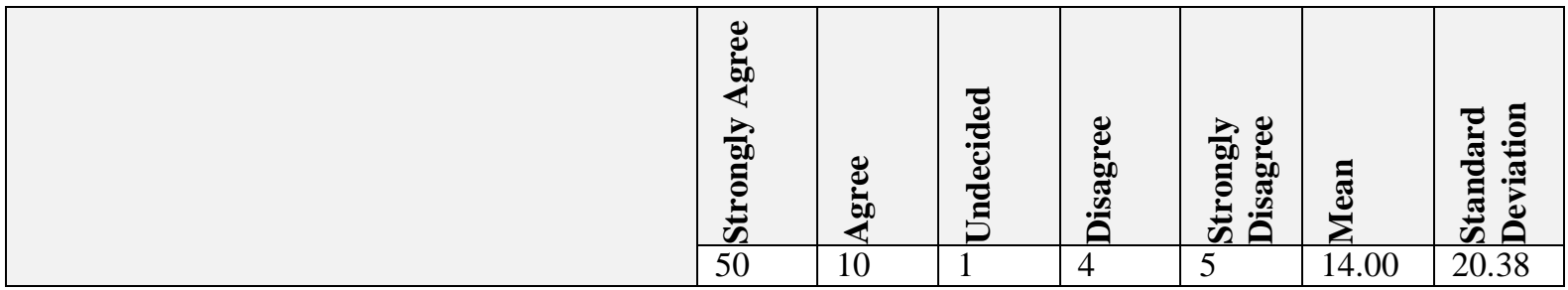

Source: Research Findings

There is room for improvement as majority of the respondents welcomed the need for the development of a Centralized Security Information System for efficient communication.

Table7. There is also an urgent need to train all police staff on ICT skills

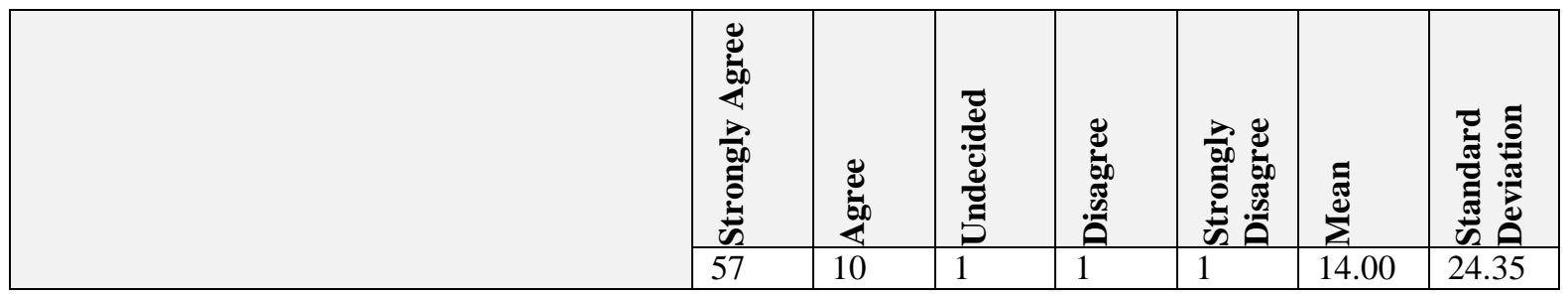

Source: Research Findings

Many of the respondents showed high level of interest in ICT skill development in order to improve their communication and policing skills.

\section{Summary, CONCluSiON AND RECOMMENDATIONS}

\subsection{Summary}

People with little or no personal contact with police form perceptions, as well, although they are shaped vicariously, through what they hear from friends and family and what they see in the news and entertainment media. This is a particularly difficult communications challenge for the police, as every interaction with the public, every news story, and every account of an encounter with the police relayed to family and friends contributes to their image and community perceptions of effectiveness

\subsection{Conclusion}

Effective communication provides police executives with a vital tool for co-ordinating the activities of the department. Since co-ordination is concerned with the interrelationships of separate police activities, it can be no better than the transfer of information about activities to a point or points in the department, where dovetailing takes place.

\subsection{Recommendations}

The study recommended that Communication is a two-way process. In order to make a proper decision, the police executive should have available information and knowledge within the department, some which may be quite removed from him. If decisions are to be effective, unobstructed flow of information to the top of the department must be assured.

\subsection{Limitations of the Study}

Communication and Effective Policing in Nigeria is a very wide and interesting discussion. However, the study failed to cover many Divisional Police Headquarters for more respondents due to insufficient time and resources.

\section{REFERENCES}

[1] Famega C. (2005), Managing Police Patrol Time: The Role of Supervisor Directives, Justice Quarterly, 22(4), 540 - 559, doi: 10.1080/07418820500364692

[2] Frank J. (2005), Managing Police Patrol Time: The Role of Supervisor Directives, Justice Quarterly, 22(4), 540 - 559, doi: 10.1080/07418820500364692 
[3] Ingram R. (2013), A Multi-Level Framework for Understanding Police Culture: The role of the workgroup Criminology, 51(2), 365 - 397, doi: 10.1111/1745-9125.12009

[4] Jablin M. (1979), Superior Subordinate Communication: The state of the art, Psychological Bulletin 86(6), $1201-1222$

[5] Mazerolle L. (2005), Managing Police Patrol Time: The Role of Supervisor Directives, Justice Quarterly, 22(4), 540 - 559, doi: 10.1080/07418820500364692

[6] Nwachukwu E. (2012), Security Challenges and the Reform of Nigerian Police, File 11H: The Police 7. Ltn: an International Publication

[7] Oyemwinmina C. (2016), Analysis towards effective policing in Nigeria, an International Multidisciplinary Journal Ethopia, 10(1), $61-72$

[8] Paoline E. (2013), A Multi-Level Framework for Understanding Police Culture: The role of the workgroup Criminology, 51(2), 365 - 397, doi: 10.1111/1745-9125.12009

[9] Terrill W. (2013), A Multi-Level Framework for Understanding Police Culture: The role of the workgroup Criminology, 51(2), 365 - 397, doi: 10.1111/1745-9125.12009

Citation: Ibikunle Olayiwola Ajisafe, Ibitoye Pius Odunayo. "Communication and Effective Policing in Nigeria". International Journal of Media, Journalism and Mass Communications (IJMJMC), vol 6, no. 2, 2020, pp. 14-20 doi: http://dx.doi.org/10.20431/2454-9479.0602002

Copyright: (C) 2020 Authors. This is an open-access article distributed under the terms of the Creative Commons Attribution License, which permits unrestricted use, distribution, and reproduction in any medium, provided the original author and source are credited. 